\title{
Household biomass fuel use, asthma symptoms severity, and asthma underdiagnosis in rural schoolchildren in Nigeria: a cross-sectional observational study
}

Oluwafemi Oluwole ${ }^{1,4}$, Ganiyu O. Arinola², Dezheng Huo ${ }^{3}$ and Christopher O. Olopade ${ }^{4^{*}}$

\begin{abstract}
Background: In 2014, the International Study of Asthma and Allergies in Childhood (ISAAC) reported that the highest prevalence of symptoms of severe asthma was found in the low- and middle-income countries (LMICS), including Nigeria. While exposure to biomass fuel use may be an important risk factor in the development of asthma, its association with asthma symptoms severity has not been well-established. The aim of this study is to extend the spectrum of environmental risk factors that may be contributing towards increasing asthma morbidity, especially asthma symptoms severity in rural schoolchildren in Nigeria and to examine possible asthma underdiagnosis among this population.
\end{abstract}

Methods: Authors conducted a cross-sectional survey in three rural communities in Nigeria. Asthma symptoms were defined according to the ISAAC criteria. Information on the types of household fuel used for cooking was used to determine household cooking fuel status. Asthma symptoms severity was defined based on frequencies of wheeze, day- and night-time symptoms, and speech limitations. Logistic regression analyses were used to explore associations.

Results: A total of 1,690 Nigerian schoolchildren participated in the study. Overall, 37 (2.2\%) had diagnosed asthma and 413 (24.4\%) had possible asthma (asthma-related symptoms but not diagnosed asthma). Children from biomass fuel households had higher proportion of possible asthma (27.7 vs. $22.2 \% ; p<0.05)$ and symptoms of severe asthma (18.2 vs. $7.6 \% ; p=0.048)$. In adjusted analyses, biomass fuel use was associated with increased odds of severe symptoms of asthma [odds ratios $(\mathrm{OR})=2.37 ; 95 \% \mathrm{Cl}: 1.16-4.84$ ], but not with possible asthma (OR=1.22; 95\% Cl: 0.95-1.56).

Conclusion: In rural Nigerian children with asthma symptoms, the use of biomass fuel for cooking is associated with an increased risk of severe asthma symptoms. There is additional evidence that rural children might be underdiagnosed for asthma.

Keywords: Biomass fuel, Asthma severity, Possible asthma, Underdiagnosis, Rural children, Nigeria

\footnotetext{
* Correspondence: solopade@bsd.uchicago.edu

${ }^{4}$ Department of Medicine and The Center for Global Health, University of

Chicago, 5841 S Maryland Avenue, MC 6076, Chicago, IL 60637, USA

Full list of author information is available at the end of the article
}

(c) The Author(s). 2017 Open Access This article is distributed under the terms of the Creative Commons Attribution 4.0 International License (http://creativecommons.org/licenses/by/4.0/, which permits unrestricted use, distribution, and reproduction in any medium, provided you give appropriate credit to the original author(s) and the source, provide a link to the Creative Commons license, and indicate if changes were made. The Creative Commons Public Domain Dedication waiver (http://creativecommons.org/publicdomain/zero/1.0/) applies to the data made available in this article, unless otherwise stated. 


\section{Background}

Roughly 334 million people worldwide suffer from asthma, and the prevalence is increasing particularly among children [1]. Reasons for this trend are currently unclear, but factors including lifestyle changes [1-3], environmental challenges (such as traffic-related pollution) [4], and tobacco smoke exposure [2, 5], dust mites [6], indoor dampness and molds [7], and pets [4] have been implicated. Additionally, household air pollution (HAP) from the use of biomass for cooking is increasingly being recognized as a risk factor for asthma and other respiratory symptoms, especially in lowand middle-income countries (LMIC) $[8,9]$.

While asthma remains the most common chronic disease in children and accounts for a substantial burden of healthcare costs globally [1], the severity of symptoms in affected children is variable; some children are affected to a limited degree, while others suffer from severe symptoms with frequent exacerbations and possible hospitalization [10]. Hence, the assessment of the degree of symptoms severity and associated risk factors has become an integral part of childhood asthma management guidelines [10]. Several studies have shown that using open fire for cooking was adversely associated with an increased risk of asthma and asthma-related symptoms $[8,9,11,12]$. However, few studies have investigated the role of exposure to smoke from biomass use on the degree of asthma and asthma symptoms severity or the frequency of symptom exacerbations.

The International Study of Asthma and Allergies in Childhood (ISAAC) estimated that the prevalence of asthma symptoms among children in Nigeria has risen from $10.7 \%$ in 1999 to approximately $20 \%$ in 2014 [1]. Despite the increasing prevalence of symptoms suggestive of asthma, the prevalence of physician-diagnosed asthma among children also remains relatively low [13]; this indicates potential underdiagnosis of asthma. Though some studies have investigated the relationships between asthma, lung health, and biomass smoke exposure in Nigeria [14-18], none have investigated the potential role of biomass fuel use on asthma symptoms severity.

With over $70 \%$ of rural Nigerian households relying on biomass fuels for cooking [19], an urgent need exists for broadening the understanding of the link between household biomass fuel use and symptoms severity in children with asthma or asthma-related symptoms. Thus, a crosssectional survey was performed to evaluate possible relationships between household biomass fuel use and the degree of asthma symptoms severity in rural Nigerian schoolchildren. Furthermore, the authors sought to determine potential asthma underdiagnosis in this population by assessing the proportion of children with possible asthma (defined as children reporting combinations of symptoms suggestive of asthma, but who have not been physician-diagnosed with asthma).

\section{Methods}

\section{Study population}

The study was conducted among schoolchildren (aged 6-21 years) from 3 similar, contiguous rural communities in southwest Nigeria: Aba-Nla, Eruwa, and IgboOra, all of which are located 40 to $100 \mathrm{~km}$ from Ibadan, a major urban center. The major source of occupation for households in these communities was farming. Hence, the majority of households are largely dependent on biomass fuel for daily cooking and energy needs; and spend, on average, five hours per day cooking with biomass fuels [16]. As a result, women and children receive substantial daily biomass smoke exposure. All 16 schools in these communities (9 secondary schools, 7 primary schools) were approached for the study. A total of 2,315 study packages, including an information letter and survey were distributed to parents through the schools for completion. Surveys were then returned to the school where they were collected by research staff. Data from 1,690 questionnaires (those which were completed and returned to schools for pick-up) form the basis of this report.

\section{The survey}

The ISAAC questionnaire, with some modifications based on the objective of the study, was administered [20] for completion by the parent of each participating student. In addition to completing the validated asthma and respiratory symptoms portions of the modified ISAAC questionnaires, parents or guardians also completed questions on household fuel type use for cooking. The questionnaire was translated from English to Yoruba (the common language in the community) and was then reversetranslated for accuracy at the Department of Linguistics at the University of Ibadan. The translated version of this questionnaire was pilot-tested in our initial study in similar rural communities [16] and adjusted after discussions with other health workers and community representatives.

\section{Operational definition of variables}

Information on respiratory health outcomes of physiciandiagnosed asthma and current wheeze was ascertained from the modified ISAAC questionnaire. The inclusion criteria for diagnosed asthma (probable asthma), possible asthma, and no asthma are presented in Table 1. "Physician-diagnosed asthma" was operationally defined as a positive response on the questionnaire to: 1) child had a history of physician-diagnosed asthma, 2) child had any episode of asthma in the past 12 months, and 3) child had taken prescribed asthma medication in the past 12 months. Children with "possible asthma" were defined as children with positive responses to wheeze or whistling symptoms in the chest, dry cough, and activity limitation, but who had never been diagnosed with asthma by a physician or 
Table 1 Asthma and asthma-like symptoms questions from survey used to classify children into asthma groups

1. Has a doctor ever said your child has asthma?
1a. If "yes" has this been in the past 12 months?
2. In the last 12 months, has your child taken asthma medication
prescribed by a doctor?
3. Has your child ever had wheeze or whistling sound in the chest?
3a If "yes" has this happened in the past 12 months?
In the last 12 months, has your child's sleep been disturbed due to
breathing problems (e.g., wheezing or whistling in the chest,
coughing, shortness of breath, chest tightness)
In the last 12 months, has your child's chest sounded wheezy or
coughed during or after exercise when he or she did not
have a cold?

Doctor-diagnosed asthma (probable asthma): Primarily "Yes" to questions 1-2 and "Yes" to at least one question between questions 3 and 5; Possible asthma ("At-Risk"): "Yes" to one or a combination of two or more questions between questions 3 and 5; No asthma: Response of "No" to all questions

other health professional. Current wheeze status was assigned with the question: "Has your child ever had wheeze or whistling in the chest in the past 12 months?" Additionally, symptoms of severe asthma were defined as children with current wheeze who in the past 12 months had 1) 4 or more attacks of wheeze, 2) had 1 or more night sleep disturbance per week, or 3) had experienced wheeze that was severe enough to prevent the child from completing 1-2 words at a time between breaths [9]. Based on the combination of 2 or more of these characteristics among the wheezing children, symptom severity was classified into "mild/moderate persistent asthma symptoms" and "severe persistent asthma symptoms".

Information on biomass smoke exposure was obtained for each child based on household cooking fuel types. Each parent/guardian responded to the question: "What fuel type is mainly used for cooking in your house?" Parent/guardians then indicated which fuel(s) were used in the household from the following list: "cow dung/animal residue," "firewood," "charcoal," "liquefied petroleum gas (LPG)," "electricity," and "other." These responses were used to group children into 2 distinct categories; children from parents choosing cow dung/crop residue, firewood, charcoal, or a combination of 2 or more of these household fuel types were classified as "children from biomass fuel households," and the rest were classified as children from "no biomass fuel households".

Finally, information on covariates of importance such as age, sex, body mass index (BMI), maternal levels of education, passive tobacco smoke exposure, and pet ownership were obtained. BMI was calculated as weight in kilograms divided by height in centimeters as reported on the questionnaire. Childhood overweight status was defined according the international cut-off value (equivalent to a body mass index of, or greater than, $25 \mathrm{~kg} / \mathrm{m}^{2}$ [21]. The following variables were included in the multivariable regression models: mother's education level, pet ownership, exposure to environmental tobacco smoke, sex, BMI, and age [22-25].

\section{Statistical analysis}

Data processing and statistical analyses were performed using Statistical Package for the Social Science (SPSS) version 23 (SPSS Inc. Armonk, NY: IBM Corp.) and the Statistical Analysis System (SAS) version 9.4 (SAS Institute Inc., Cary, NC, USA). An alpha level of 0.05 defined statistical significance. Categorical demographics, environmental, and respiratory symptoms, (including severity categories) were compared between children from the two biomass user groups using the $\chi^{2}$ test, while continuous variable was compared using independent $t$-tests. Binary and multivariate logistic regression analyses were performed to assess the relationships between household cooking fuel types and possible asthma as well as asthma symptoms severity among children with wheezing symptom. Variables were included in the multivariate models based on statistical significance in the univariate analysis $(p \leq 0.25)$ and biological/clinical importance. The strengths of the associations were assessed using odds ratios (ORs) with 95\% confidence intervals (95\%CI).

\section{Results}

Of the 1,690 children studied, 865 (51.1\%) were from households using biomass fuels for cooking and 825 (48.9\%) were from households using cleaner fuels. Key demographic and environmental characteristics by household's fuel status are presented in Table 2. Sex distributions were similar between the 2 groups and children from biomass fuel households were about 0.6 years younger on average than children from households using cleaner fuels. There were significant differences between the 2 groups for mother's levels of education and a higher proportion of children from no biomass fuel households were more likely to be overweight. When comparing environmental characteristics, only exposure to pets (cat and dog) differed significantly between the 2 groups $(p=0.031)$.

There were 37 (2.2\%) children with doctor-diagnosed asthma. Among children who were not diagnosed with asthma, a higher proportion of children from biomass fuel households had possible asthma (Table 3; 27.7 vs. $22.2 \%)$. The prevalence of asthma and current wheeze did not differ significantly between the 2 groups.

Among children with current wheeze (Table $4 ; n=156$ ), the authors also assessed the prevalence of night and daytime symptoms of asthma and the degree of severity of asthma symptoms. The use of biomass fuels for cooking was not statistically related to number of wheezing episodes, waking at night due to wheezing symptoms, or speech limitations due to symptoms. However, a higher proportion of children from biomass fuel households were 
Table 2 Personal and environmental characteristics of children by household biomass fuel status

\begin{tabular}{|c|c|c|c|c|}
\hline & Overall $(n=1690)$ & Biomass fuel households $(n=865)$ & No biomass fuel households $(n=825)$ & $P$ value \\
\hline \multicolumn{5}{|l|}{ Demographics } \\
\hline Mean age, years $( \pm S D)$ & $13.6(2.7)$ & $13.3(2.7)$ & $13.9(2.6)$ & $<0.001$ \\
\hline \multicolumn{5}{|l|}{ Sex, $n(\%)$} \\
\hline Male & $873(51.7)$ & $433(50.1)$ & $440(53.3)$ & 0.178 \\
\hline \multicolumn{5}{|l|}{ Mother's level of education, $n(\%)$} \\
\hline$\geq$ High school & $200(14.6)$ & $77(11.0)$ & $123(18.4)$ & $<0.001$ \\
\hline \multicolumn{5}{|l|}{ Body mass index (BMI), $n(\%)$} \\
\hline Overweight & $26(1.5)$ & $6(0.7)$ & $20(2.4)$ & 0.004 \\
\hline \multicolumn{5}{|l|}{ Environmental exposure, $n(\%)$} \\
\hline Parental smoke & $13(0.8)$ & $8(0.9)$ & $5(0.6)$ & 0.453 \\
\hline Environmental tobacco smoke & 11.2 & 12.6 & 9.7 & 0.058 \\
\hline Pet ownership, cat & $232(13.7)$ & $128(14.8)$ & $104(12.6)$ & 0.191 \\
\hline Pet ownership, dog & $393(23.3)$ & $218(25.2)$ & $175(21.2)$ & 0.052 \\
\hline Pet ownership, cat and dog & $517(30.6)$ & $285(32.9)$ & $232(28.1)$ & 0.031 \\
\hline
\end{tabular}

classified as having symptoms of severe asthma compared to children from cleaner fuel households (18.2 vs. $7.6 \%$; $p=0.048)$.

In univariate analysis, possible asthma and symptoms of severe asthma were positively associated with household biomass fuel types (Table 5). Similar positive associations were observed for mother's education levels, and pet ownership for possible asthma, but not for symptoms of severe asthma. After adjusting for potential confounders, the association between biomass fuel use and symptoms of severe asthma remained statistically significant, but the association for possible asthma only trends towards significance $(p=0.125)$. In addition, the associations between mother's education levels, and pet ownership for

Table 3 Respiratory outcomes among children based on household cooking fuel type

\begin{tabular}{|c|c|c|c|c|}
\hline & $\begin{array}{l}\text { Overall } \\
(n=1690)\end{array}$ & $\begin{array}{l}\text { Biomass fuel } \\
\text { households } \\
(n=865)\end{array}$ & $\begin{array}{l}\text { No biomass fuel } \\
\text { households } \\
\text { ( } n=825)\end{array}$ & $P$ value \\
\hline \multicolumn{5}{|c|}{ Respiratory outcomes, $n(\%)$} \\
\hline \multicolumn{5}{|c|}{ Diagnosed asthma } \\
\hline Yes & $37(2.2)$ & $20(2.3)$ & $17(2.1)$ & 0.724 \\
\hline No & $1653(97.8)$ & $845(97.7)$ & $808(97.9)$ & \\
\hline \multicolumn{5}{|c|}{ Possible asthma } \\
\hline Yes & $413(24.4)$ & $234(27.7)$ & $179(22.2)$ & 0.009 \\
\hline $\mathrm{No}^{\mathrm{a}}$ & $1240(73.4)$ & $611(72.3)$ & $629(76.8)$ & \\
\hline \multicolumn{5}{|c|}{ Current wheeze } \\
\hline Yes & $156(9.2)$ & $82(9.5)$ & $74(9.0)$ & 0.676 \\
\hline No & 1514 (89.6) & $771(89.1)$ & $743(90.1)$ & \\
\hline Missing & $20(1.2)$ & $12(1.4)$ & $8(0.9)$ & \\
\hline
\end{tabular}

${ }^{\mathrm{a}}$ Children with reports of no physician-diagnosed asthma and ascertained to have no possible asthma possible asthma (not symptoms of severe asthma) remained significant. The association between sex and possible asthma was also significant but this was confined to male children only (male: $\mathrm{OR}=1.51$; $95 \% \mathrm{CI}$ : $1.04-$ 2.19; female: $\mathrm{OR}=1.00 ; 95 \% \mathrm{CI}$ : 0.70-6.35). However, the gender-based effects were not seen for symptoms of severe asthma (male: $\mathrm{OR}=2.30 ; 95 \% \mathrm{CI}$ : 0.67-7.89; female: $\mathrm{OR}=2.44$; 95\%CI: $0.93-6.35$ ). Data not shown in table.

\section{Discussion}

The use of solid fuels such as wood, charcoal, dried animal dung and agricultural residues, as sources of domestic cooking energy has, recently, received great attention. The ISAAC Phase 3 study reported that the highest prevalence of symptoms of severe asthma (among wheezing children) was found in the LMICs [26]. Factors responsible for this high prevalence are still not well evaluated.

In the current study, we demonstrated that household biomass fuel use may worsen asthma conditions in rural children with asthma or asthma-like symptoms. Wheezing children from households using biomass fuels for cooking experienced more severe asthma symptoms compared to children from households using cleaner fuels. Findings from this study also reveal that despite a lower prevalence of diagnosed asthma among children from both biomass fuel groups, a higher proportion of children were classified as having possible asthma in both groups (which is significantly higher in children from biomass fuel group). This suggests that majority of children in the studied rural communities may probably have asthma, but are either unaware of their asthma conditions or have not yet been diagnosed by a healthcare professional as having asthma. 
Table 4 Prevalence and severity of symptoms among children with current wheeze by household fuel status $(n=156)$

\begin{tabular}{|c|c|c|c|}
\hline & Biomass fuel households $(n=77)$ & No biomass fuel households $(n=79)$ & $P$ value \\
\hline \multicolumn{4}{|l|}{ Wheeze frequency, $n$ (\%) } \\
\hline$<4$ attacks per week & $64(83.1)$ & $68(86.1)$ & \multirow[t]{2}{*}{0.609} \\
\hline$\geq 4$ attacks per week & $13(16.9)$ & $11(13.9)$ & \\
\hline \multicolumn{4}{|l|}{ Sleep disturbance due to wheeze, $n(\%)$} \\
\hline$<1$ night of sleep per week & $53(68.8)$ & $58(73.4)$ & \multirow[t]{2}{*}{0.527} \\
\hline$\geq 1$ night of sleep per week & $24(31.2)$ & $21(26.6)$ & \\
\hline \multicolumn{4}{|l|}{ Difficulty in completing sentence, $n(\%)$} \\
\hline No speech limitation & 49 (63.6) & $49(62.0)$ & \multirow[t]{2}{*}{0.835} \\
\hline Speech limit to $1-2$ words per breath & $28(36.4)$ & $30(38.0)$ & \\
\hline \multicolumn{4}{|l|}{ Symptoms severity categories, $n$ (\%) } \\
\hline Mild/moderate persistent & $63(81.8)$ & $73(92.4)$ & \multirow[t]{2}{*}{0.048} \\
\hline Severe persistent & $14(18.2)$ & $6(7.6)$ & \\
\hline
\end{tabular}

Several features of the rural environment (including socio-economic status [SES], access to healthcare, dust exposure) have been observed to worsen asthma condition and symptoms severity in children [24, 27]. This study provides further evidence to support a connection between biomass fuel use and the exacerbation of asthma symptoms in rural settings where the practice is predominant.

Few studies to date have investigated the effect of HAP on asthma symptoms severity as the main focus, having instead chosen to investigate the prevalence and incidence of asthma. In a cross-sectional study among 1,058 children in Guatemala, the use of open fire for cooking was associated with an increased risk of wheezing episode, night sleep disturbance due to wheeze, and speech limitation between breaths due to wheezing symptoms, albeit non-significantly except for speech limitation [28]. The findings from the current study confirmed those of the
Phase III global investigation of childhood asthma prevalence by the ISAAC team, where the use of open fire was observed to increase the risk of current symptoms of severe asthma in children 6-7 years old $(\mathrm{aOR}=1.79$; 95\%CI: 1.18 2.70) [9]. However, in the ISAAC study, the report of open fire for cooking was 0 and $18 \%$ for children aged $6-7$ years and 13-14 years, respectively, in the African region; as such, its findings could not be generalized to the African region. The study at hand demonstrates a possible link between the use of open fire and symptoms of severe asthma, but in a different rural African population that primarily cook with biomass fuel. Although studies have shown that rural environment may confer some protections against the development of asthma in children [29-32], results of this study further demonstrate that some rural areas may have certain environmental factors that place children at the same risk for development of asthma; and once children

Table 5 Associations between personal and environmental characteristics and respiratory health outcomes and severity among the study population $(n=1690)$

\begin{tabular}{|c|c|c|c|c|}
\hline & \multicolumn{2}{|l|}{ Possible asthma $(n=413)$} & \multicolumn{2}{|c|}{ Symptoms of severe asthma $^{\mathrm{b}}(n=156)$} \\
\hline & Univariate Model OR (95\%Cl) & Adjusted Model* OR (95\%Cl) & Univariate Model OR (95\%Cl) & Adjusted Model ${ }^{\complement}$ OR $(95 \% \mathrm{Cl})$ \\
\hline \multicolumn{5}{|l|}{ Household fuel type } \\
\hline No biomass fuel & 1.00 & 1.00 & 1.00 & 1.00 \\
\hline Biomass fuel & $1.35(1.08-1.68)^{a}$ & $1.22(0.95-1.56)$ & $1.92(1.02-3.61)^{a}$ & $2.37(1.16-4.84)^{a}$ \\
\hline \multicolumn{5}{|l|}{ Sex } \\
\hline Male vs. female & $0.82(0.65-1.02)$ & $0.83(0.39-0.88)^{a}$ & $1.00(0.53-1.87)$ & $1.14(0.55-2.37)$ \\
\hline Age (per year) & $0.96(0.92-1.00)$ & $0.95(0.91-1.00)$ & $0.94(0.83-1.07)$ & $0.95(0.81-1.10)$ \\
\hline \multicolumn{5}{|l|}{ Mother education } \\
\hline$<$ High school & 1.00 & 1.00 & 1.00 & 1.00 \\
\hline$\geq$ High school & $0.54(0.36-0.80)^{a}$ & $0.58(0.39-0.88)^{a}$ & $0.70(0.23-2.15)$ & $0.65(0.20-2.06)$ \\
\hline \multicolumn{5}{|l|}{ Pet ownership } \\
\hline Yes vs. no & $1.50(1.18-1.89)^{a}$ & $1.57(1.20-2.04)^{a}$ & $1.11(0.57-2.17)$ & $1.03(0.48-2.18)$ \\
\hline
\end{tabular}

${ }^{a} P<0.05$

${ }^{\text {b}}$ Symptoms of mild/moderate persistent asthma was used as reference category

${ }^{c}$ Model adjusted for each variable in the table as well as body mass index and environmental tobacco smoke exposure 
are afflicted with asthma or have asthma symptoms, certain rural exposure may aggravate the severity of their respiratory conditions. Therefore, regardless of the actual prevalence of asthma in the population, our study further supports the concept that children from rural settings or LMICs with exposure to biomass fuel may be at increased risk for more severe asthma.

Overall, a $24 \%$ prevalence of possible asthma (unassociated with a diagnosis) was observed, suggesting that the true asthma prevalence in this population may be higher than previously known due to possible underdiagnosis of asthma among rural children. Although urban children were not recruited in this study, the findings show a similar trend to observations from a study in the USA where children from rural settings were less likely to be diagnosed with asthma and more likely to be characterized as "at-risk" of asthma (27.8\%) compared to urban children (24.6\%) [33].

Studies have revealed some factors that may contribute to asthma underdiagnosis among children, especially rural children, including poor access to healthcare for symptoms reporting and diagnosis [34] and/or diagnostic differences in asthma recognition and labelling by physicians [35]. In the present study, the authors do not feel that the reason for underdiagnosis among children in these rural settings was due to diagnostic differences in asthma recognition because the survey instrument used was translated from English to the Yoruba language and reverse-translated by expert translators for clarity and better understanding of symptoms; it was also piloted by the authors in similar rural communities [16]. Instead, it may be due to lack of symptoms awareness among parents and accessibility to healthcare centers, which could signify target interventions for children's respiratory health in these communities. In the ISAAC studies, the overall prevalence of asthma symptom (current wheeze) among children in Nigeria has been observed to have increased between Phase 1 and Phase 3 of the study ( 4.5 to $5.6 \%$, respectively, for 6-7 year agegroup and 10.7 to $13 \%$, respectively, for the 13-14 year age-group) [36]. One of the explanations for the apparent increase was a greater awareness of asthma-related symptoms, especially in the LMICs. However, the relatively low asthma prevalence observed in our study population, despite a higher prevalence of asthma-related symptoms, suggests improved efforts to increase awareness about asthma symptoms, especially wheezing (which may be a subjective complaint that could be described and interpreted in several ways), among rural populations in Nigeria. This could improve symptoms reporting, better diagnosis of asthma and provide accurate estimate of the disease prevalence among children in Nigeria.

We must consider limitations of our study. First, since households can use a combination of fuel types, there could be possibility of exposure misclassification which may inflate our results. However, in the survey questionnaire, parents had the options to choose from different energy sources: "cow dung/animal residue," "firewood," "charcoal," "liquefied petroleum gas (LPG)," "electricity," and "other. If parents chose "other," they also need to specify which fuel they used. To minimize exposure misclassification, only children from parents using cow dung/crop residue, firewood, charcoal, or a combination of two or more of these household fuel types were classified as children from households using biomass fuels. Moreover, the survey questionnaire was translated from English to Yoruba (the commonly spoken language in the community) for easy understanding by the parents. Therefore, while it may be difficult to completely eliminate exposure misclassification in this study, we would expect that this would occur non-differentially between the biomass fuel user groups allowing our interpretation of the results comparing the two groups to remain valid. Another limitation of this study is the lack of information on household SES and accessibility to healthcare, which could be related to asthma symptoms severity. It is possible that many of the children with severe symptoms of asthma were neither involved in cooking activities nor has at any point in time being exposed to biomass smoke. Symptoms severity might have occurred due to lack of access to healthcare centers for symptoms diagnosis or lack of appropriate symptoms management due to parental financial constraints. Such information would have strengthened the results of the study by enabling the separation of current asthma symptoms that are related to chronic exposure to biomass fuel from that associated with family SES. However, because mothers' education level, used as proxy indicator of SES in the multivariate analysis, was not significant in this study, we do not believe other SES indicators would have changed our results significantly since the rural populations involved in this study are mostly homogeneous. Finally, we did not recruit children from urban centres in this study. Although, we believe that some households in urban centers in Nigeria also use biomass fuels in combination with other cleaner fuels (e.g., LPG, kerosene and electricity) for cooking and energy needs, we limited recruitment of our participants to communities that are predominantly homogeneous in terms of socioeconomic status, home construction, and access to health care to minimize residual confounders in our results. However, whether the patterns of risk of symptoms of severe asthma observed in rural children exposed to biomass fuels in the current study mirror similar pattern in urban children, with varied household characteristics, or the risk could be mediated by a combination of other factors warrants further investigation.

Large sample size and the use of standardized and validated instruments across all rural regions included in 
this study are the strengths of this study. This allowed us adequate statistical power to consider associations between asthma severity and biomass fuel, as part of the rural population exposure characteristics. Also, the standardized methods of assessment were identical in all locations and biomass fuel user groups so that the observed differences could not be attributed to methodological discrepancies.

\section{Conclusion}

The current study demonstrated worse asthma symptoms among children exposed to HAP from burning solid fuels and possible asthma underdiagnosis in rural Nigerian schoolchildren. Children from these rural settings were also more likely to be have possible asthma and less likely to be diagnosed as asthmatic. The study further highlights the role of biomass fuel use as a potential risk factor for increasing asthma morbidity in rural Nigerian settings and provides an opportunity for utilizing schools to identify children at risk for asthma. It is currently impossible to eliminate the use of solid fuels as sources of domestic cooking energy in rural communities in Nigeria. Therefore, findings from this study call for integrated interventions to reduce HAP in order to improve lung health among children and a need for school-based health centers for childhood asthma screening and diagnosis. However, until such an upstream intervention can be achieved, avoidance of factors that could trigger and/or worsen asthma, such as the reduction of exposure to biomass fuel smoke from cooking, may form a crucial component of asthma management guidelines for children in rural Nigeria.

\section{Abbreviations \\ BMI: Body Mass Index; Cl: 95\% confidence interval; HAP: Household Air Pollution; ISAAC: International Study of Asthma and Allergies in Childhood; LMICs: Low- and Middle-Income Countries; LPG: Liquefied Petroleum Gas; OR: Odds ratio}

\section{Acknowledgement}

The authors wish to thank all staff of the Healthy Life for All Foundation (HLF), Ibadan, Nigeria for assistance with project execution and technical support. We also wish to thank the school principals, parents, and schoolchildren who took time to take part in this study and Ms. Monica Palese for editorial assistance.

\section{Funding}

This study was funded by grant from the Ralph and Marion FALK Medical Trust, Chicago, USA and the Healthy Life for All Foundation (HLF), Ibadan, Nigeria.

\section{Availability of data and material}

Please contact authors for data request.

\section{Authors' contributions}

$\mathrm{OO}, \mathrm{GOA}$ and $\mathrm{COO}$ contributed substantially to the study concept, design, data collection and manuscript preparation. They had full access to the data and take responsibility for the integrity of the data. $\mathrm{OO}$ and $\mathrm{DH}$ contributed substantially to statistical data analysis and interpretation, manuscript preparation and take responsibility for the accuracy of the data analysis. All authors read and approved the final manuscript.

\section{Competing interest}

The authors declare that they have no competing interests.

\section{Consent for publication}

Signed informed consent and assent forms were obtained from participating parents and children, respectively, for the publication of this study.

\section{Ethical approval and consent to participate}

Participation in the study required parental or guardian consent and child assent forms, which denoted voluntary consent. Approval to conduct the study was also obtained from the Institutional Review Board on Human Research at the University of Ibadan, Nigeria (Approval Number: UI/EC/09/ 0133) and at The University of Chicago, USA (Approval Number: 09-336-B). Additional approval was obtained from the Oyo State Ministry of Education in Ibadan, Nigeria and from all principals of the schools involved.

\section{Author details}

'Department of Community Health and Epidemiology and the Canadian Centre for Health and Safety in Agriculture, College of Medicine, University of Saskatchewan, Saskatoon, SK, Canada. ${ }^{2}$ College of Medicine, University of Ibadan, Ibadan, Oyo State, Nigeria. ${ }^{3}$ Department of Public Health Science, University of Chicago, Chicago, IL, USA. ${ }^{4}$ Department of Medicine and The Center for Global Health, University of Chicago, 5841 S Maryland Avenue, MC 6076, Chicago, IL 60637, USA.

Received: 30 September 2016 Accepted: 14 December 2016

Published online: 05 January 2017

\section{References}

1. Asher I, Pearce N. Global burden of asthma among children. Int J Tuberc Lung Dis. 2014;18(11):1269-78.

2. Han YY, Lee YL, Guo YL. Indoor environmental risk factors and seasonal variation of childhood asthma. Pediatr Allergy Immunol. 2009;20(8):748-56.

3. Simons $\mathrm{E}, \mathrm{To} \mathrm{T}$, Dell $\mathrm{S}$. The population attributable fraction of asthma among Canadian children. Can J Public Health. 2011;102(1):35-41.

4. Brunekreef B, Stewart AW, Anderson HR, Lai CKW, Strachan DP, Pearce N, et al. Self-reported truck traffic on the street of residence and symptoms of asthma and allergic disease: a global relationship in ISAAC phase 3. Environ Health Perspect. 2009;117(11):1791-8.

5. Lawson JA, Dosman JA, Rennie DC, Beach J, Newman SC, Senthilselvan A. Relationship between indoor environment and asthma and wheeze severity among rural children and adolescents. J Agromedicine. 2009;14(2):277-85.

6. Celedon JC, Milton DK, Ramsey CD, Litonjua AA, Ryan L, Platts-Mills TA, et al. Exposure to dust mite allergen and endotoxin in early life and asthma and atopy in childhood. J Allergy Clin Immunol. 2007;120(1):144-9.

7. Weinmayr G, Gehring U, Genuneit J, Büchele G, Kleiner A, Siebers R, et al. Dampness and moulds in relation to respiratory and allergic symptoms in children: results from Phase Two of the International Study of Asthma and Allergies in Childhood (ISAAC Phase Two). Clin Exp Allergy. 2013;43(7):762-74.

8. Po JY, FitzGerald JM, Carlsten C. Respiratory disease associated with solid biomass fuel exposure in rural women and children: systematic review and meta-analysis. Thorax. 2011;66(3):232-9.

9. Wong GW, Brunekreef B, Ellwood P, Anderson HR, Asher MI, Crane J, et al. Cooking fuels and prevalence of asthma: a global analysis of phase three of the International Study of Asthma and Allergies in Childhood (ISAAC). Lancet Respir Med. 2013;1(5):386-94.

10. Taylor DR, Bateman ED, Boulet LP, Boushey HA, Busse WW, Casale TB, et al. A new perspective on concepts of asthma severity and control. Eur Respir J. 2008;32(3):545-54

11. Kraai S, Verhagen LM, Valladares E, Goecke J, Rasquin L, Colmenares P, et al. High prevalence of asthma symptoms in Warao Amerindian children in Venezuela is significantly associated with open-fire cooking: a crosssectional observational study. Respir Res. 2013;14(76):1-10.

12. Trevor J, Antony $\mathrm{V}$, Jindal SK. The effect of biomass fuel exposure on the prevalence of asthma in adults in India - review of current evidence. J of Asthma. 2014;51(2):136-41.

13. Musa BM, M.D. A. Asthma prevalence in Nigerian adolescents and adults: systematic review and meta-anaylsis. Afr J Respir Med. 2014;10(1):4-9.

14. Ana GR, Adeniji B, Ige O, Oluwole O, Olopade CO. Exposure to emissions from firewood cooking stove and the pulmonary health of 
women in Olorunda community, Ibadan, Nigeria. Air Qual Atmos Health. 2013;6(2):465-71.

15. Mustapha BA, Blangiardo M, Briggs DJ, Hansell AL. Traffic air pollution and other risk factors for respiratory illness in schoolchildren in the niger-delta region of Nigeria. Environ Health Perspect. 2011;119(10):1478-82.

16. Oluwole O, Ana GR, Arinola GO, Wiskel T, Falusi AG, Huo D, et al. Effect of stove intervention on household air pollution and the respiratory health of women and children in rural Nigeria. Air Qual Atmos Health. 2013;6(3):553-61.

17. Thacher JD, Emmelin A, Madaki AJ, Thacher TD. Biomass fuel use and the risk of asthma in Nigerian children. Respir Med. 2013;107(12):1845-51.

18. Umoh V, Peters E, Erhabor G, Ekpe E, Ibok A. Indoor air pollution and respiratory symptoms among fishermen in the Niger delta of Nigeria. Afr J Respir Med. 2013;9(1):17-21.

19. Obueh J. Methanol stoves for indoor air pollution reduction in Delta State, Nigeria. Bioling Point. 2006;52:26-9.

20. Asher Ml, Anderson HR, Stewart AW, Crane J. Worldwide variations in the prevalence of asthma symptoms: the International Study of Asthma and allergies in Childhood (ISAAC). Eur Respir J. 1998;12:315-35.

21. Cole TJ, Bellizzi MC, Flegal KM, Dietz WH. Establishing a standard definition for child overweight and obesity worldwide: international survey. BMJ. 2000; 320:1240-3.

22. Alaniz-Flores A, Canseco-Raymundo Mdel R, Granados-Gomez A, BecerrilÁngeles M. Association between obesity and asthma severity in children. Rev Alerg Mex. 2013;60(3):117-22.

23. Gent JF, Belanger K, Triche EW, Bracken MB, Beckett WS, Leaderer BP. Association of pediatric asthma severity with exposure to common household dust allergens. Environ Res. 2009;109(6):768-74.

24. Higgins PS, Wakefield D, Cloutier MM. Risk factors for asthma and asthma severity in nonurban children in Connecticut. Chest. 2005;128(6):3846-53.

25. Rodriguez MC, Sossa M, Goss CH. Factors associated with severe disease in a population of asthmatic children of Bogota, Colombia. J of Asthma. 2008; 45(2):141-7.

26. Lai CKW, Beasley R, Crane J, Foliaki S, Shah J, Weiland S, et al. Global variation in the prevalence and severity of asthma symptoms: Phase Three of the International Study of Asthma and Allergies in Childhood (ISAAC). Thorax. 2009;64(2):476-83.

27. Horner SD. Childhood asthma in a rural environment: implications for clinical nurse specialist practice. Clin Nurse Spec. 2008;22(4):192-8.

28. Schei MA, Hessen JO, Smith KR, Bruce N, McCraken J. Lopez. Childhood asthma and indoor woodsmoke from cooking in Guatemala. J Expo Anal Environ Epidemiol. 2004;14 Suppl 1:S110-7.

29. Patrick GH, Peter DS. Environmental Microbial Exposure and Protection against Asthma. N Engl J Med. 2015;373:2576-78. doi:10.1056/ NEJMcibr1511291.

30. Ma Y, Zhao J, Han ZR, Chen Y, Leung TF, Wong GW. Very low prevalence of asthma and allergies in schoolchildren from rural Beijing, China. Pediatr Pulmonol. 2009;44(8):793-9.

31. Majkowska-Wojciechowska B, Pelka J, Korzon L, Kozlowska A, Kaczala $M$, Jarzesbska $M$, et al. Prevalence of allergy, patterns of allergic sensitization and allergy risk factors in rural and urban children. Allergy. 2007;62(9):1044-50.

32. Sole D, Cassol VE, Silva AR, Teche SP, Rizzato TM, Bandim LC, et al, Prevalence of symptoms of asthma, rhinitis, and atopic eczema among adolescents living in urban and rural areas in different regions of Brazil. Allergol Immunopathol. 2007;35(6):248-53.

33. Pesek RD, Vargas PA, Halterman JS, Jones SM, McCracken A, Perry TT. A comparison of asthma prevalence and morbidity between rural and urban schoolchildren in Arkansas. Ann Allergy Asthma Immunol. 2010; 104(2):125-31

34. Probst JC, Laditka SB, Wang JY, Johnson AO. Effects of residence and race on burden of travel for care: cross sectional analysis of the 2001 US National Household Travel Survey. BMC Health Serv Res. 2007;7(40):1-13.

35. Brozek G, Lawson J, Shpakou A, Fedortsiv O, Hryshchuk L, Rennie D, et al. Childhood asthma prevalence and risk factors in three Eastern European countries - the Belarus, Ukraine, Poland Asthma Study (BUPAS): an international prevalence study. BMC Pulm Med. 2016;16(11):1-11.

36. Asher Ml, Montefort S, Björkstén B, Lai CKW, Strachan D, Weiland SK, et al. Worldwide time trends in the prevalence of symptoms of asthma, allergic rhinoconjunctivitis, and eczema in childhood: ISAAC Phases One and Three repeat multicountry cross-sectional surveys. Lancet. 2006;368(9537):733-43.

\section{Submit your next manuscript to BioMed Central and we will help you at every step:}

- We accept pre-submission inquiries

- Our selector tool helps you to find the most relevant journal

- We provide round the clock customer support

- Convenient online submission

- Thorough peer review

- Inclusion in PubMed and all major indexing services

- Maximum visibility for your research

Submit your manuscript at www.biomedcentral.com/submit 